Mini Review

\title{
Architectural and functional remodeling of cardiac and skeletal muscle cells in mice lacking specific isoenzymes of creatine kinase
}

\author{
Lucia Tylková \\ Institute of Molecular Physiology and Genetics, Slovak Academy of Sciences, Bratislava, Slovakia
}

\begin{abstract}
Muscle is the major consumer of fuels and ATP in the body. Mitochondria and glycolytic complexes serve as the main energy production locations, while the highest energy demands are associated with the sarcoplasmic reticulum, myofibrillar compartments and plasma membrane. Creatine kinase (CK) is a dimeric protein, which is deeply involved in the production of high energy storage compounds. This enzyme reversibly phosphorylates creatine $(\mathrm{Cr})$ to phosphocreatine $(\mathrm{PCr})$, and it is also highly adapted to specialized muscle function. To date, four major isoenzymes of CK have been identified, two of which occur in the cytosol and two in mitochondria.

Disruption of the phosphotransfer system induced by an absence of either the sarcomeric mitochondrial CK or cytosolic CK or both isoenzymes of $\mathrm{CK}\left(\mathrm{CK}^{-/-}\right)$in muscle cells leads to morphological and functional adaptations towards preservation of muscle contractile abilities. Remodeling of the cell ultrastructure observed in $\mathrm{CK}^{-1-}$ cardiomyocytes and glycolytic fibers was associated with direct transfer of energy from places of energy production to locations of energy utilization. This direct interaction among the organelles can maintain a high ATP/ADP ratio near the cellular ATPases when CK is not functionally active. This review summarizes the function and role of CK across different muscle cells in knockout mice.
\end{abstract}

Key words: Creatine kinase - Skeletal muscle - Heart - Knockout mice - Remodeling

\section{Introduction}

The functional and structural diversity of skeletal muscles is connected with the diversity of skeletal muscle fibers. Differentiation and maturation lead to a highly complex cellular specialization and organization in adult mammalian muscle tissue. All specialized cellular functions are organized within structural and functional compartments.

Muscle cells contain specialized energy transfer systems that connect sites of energy consumption with those of energy production. The creatine kinase/phosphocreatine (CK/PCr) system plays a key role in cellular energy buffering and energy transport, particularly in muscle cells, which have high and fluctuating energy requirements (Dzeja and Terzic 2003). Besides the CK/PCr, the adenylate kinase system, glycolytic network and closer interaction between mitochondria and organelles may further aid energy transfer

Correspondence to: Lucia Tylková, Institute of Molecular Physiology and Genetics, Vlárska 5, 83334 Bratislava, Slovakia E-mail: lucia.tylkova@savba.sk within muscle cells (Xu et al. 1995; Saupe et al. 1998; Crozatier et al. 2002). These systems are competitive and can compensate for each other to maintain cellular energetics (Ventura-Clapier et al. 2004).

\section{Expression of CK isoenzymes and the role of the CK system across different muscle cells}

CK catalyzes the reversible transfer of the N-phosphoryl group from PCr to ADP to regenerate ATP. Four major CK isoenzymes have been identified to date, and their names are derived from the original isolation source. The isoenzymes were characterized on the basis of differences in gene and amino acid sequences, tissue localization and immunogenicity (Wallimann et al. 1992). There exist two cytosolic forms, namely the muscle (MM-CK) and brain (BB-CK) variants, which exist as dimers under physiological conditions (Wyss et al. 1992). Under certain circumstances, cytosolic CK can exist as a MB heterodimer. There are also two mitochondrial forms of the enzyme, the ubiquitous $\left(\mathrm{Mi}-\mathrm{CK}_{\mathrm{u}}\right)$ and the sarco- 
meric $\left(\mathrm{Mi}-\mathrm{CK}_{\mathrm{s}}\right)$ forms (Wyss et al. 1992). The mitochondrial isoforms (Mi-CK) generally exist as octamers but can be readily dissociated into dimers (Wyss et al. 1992).

Most vertebrate tissues express two CK isoenzyme combinations, either dimeric, cytosolic MM-CK together with mostly octameric $\mathrm{Mi}-\mathrm{CK}_{\mathrm{s}}$ or, alternatively, BB-CK, together with $\mathrm{Mi}-\mathrm{CK}_{\mathrm{u}}$. The $\mathrm{CK}$ isoenzyme combination, $\mathrm{MM}-\mathrm{CK}$ with $\mathrm{Mi}-\mathrm{CK}_{\mathrm{s}}$, is expressed in differentiated sarcomeric muscle, in the context of both cardiac and skeletal tissue. On the other hand, the combination of $\mathrm{BB}-\mathrm{CK}$ with $\mathrm{Mi}-\mathrm{CK}_{\mathrm{u}}$ is prominently expressed in brain, smooth muscle (Wyss et al. 1992) and endothelial cells (Decking et al. 2001).

During late fetal and neonatal development of mammals, expression of MM-CK and Mi-CK increases dramatically, whereas isoform BB-CK peaks at the time of birth and then declines, leaving only trace amounts in the heart and in the skeletal muscles at adulthood (Saupe et al. 2000; in't Zandt et al. 2003). Hybrid cytosolic MB-CK is expressed only transiently during muscle differentiation but persists at low levels in adult cardiac muscle (Wallimann et al. 1992).

Various isoforms are compartmentalized at specific intracellular sites (mitochondria, sarcoplasmic reticulum (SR), plasma membrane or myofilaments) or remain free in the cytosol. MM-CK has been identified in myofibrils and is often described as a structural protein of the M-band (Wallimann and Eppenberger 1985). This CK isoform bound to myofibrils has been shown to be functionally coupled to the myosin ATPase. This efficient coupling ensures the maintenance of a high local ATP/ADP ratio and thereby stimulates myosin ATPase activity to ensure normal kinetics of contraction (Ventura-Clapier et al. 1994). Similarly, MM-CK is strongly bound to SR membranes where it is functionally coupled to $\mathrm{Ca}^{2+}$-ATPase (Rossi et al. 1990; Minajeva et al. 1996) and ensures efficient energy provision of the SR by means of the local regeneration of ATP. A relatively small but important proportion of the MM-CK is associated with $\mathrm{Na}^{+}, \mathrm{K}^{+}$-ATPase (Wallimann et al. 1989). The Mi-CK $\mathrm{s}_{\mathrm{s}}$ is bound to the external face of the inner mitochondrial membrane. Octameric $\mathrm{Mi}-\mathrm{CK}_{\mathrm{s}}$ interacts with both the inner and the outer mitochondrial membrane at the contact sites. It is functionally coupled to the adenine nucleotide translocase (Vendelin et al. 2004; Brdiczka et al. 2006).

The CK system exhibits a high degree of plasticity in respect of special muscle functions. Two main roles have been ascribed to the CK system in muscle cells. The first role is to maintain a spatio-temporal equilibrium of adenine nucleotides (Ventura-Clapier et al. 2004). This property of the CK system is important in fast glycolytic skeletal muscles that depend to a large extent on quickly mobilizing energy reserves to enable contraction (Katz 2001). In these muscles, ATP consumption increases 100-fold within a few milliseconds of the onset of nerve stimulation (Tullson et al. 1998; Ventura-Clapier et al. 1998). Afterwards, energy stores of PCr will be replenished by anaerobic glycolysis and less importantly by mitochondrial oxidation processes.

The second role of the CK system is to ensure rapid and efficient energy transfer among mitochondria and the myosin ATPase through the associated near-equilibrium reactions (Saks et al. 1994), and through the transfer of metabolic signals back to the mitochondrial matrix (Dzeja et al. 1998; Zoll et al. 2002). This inference is consistent with the localization of CK isoenzymes on mitochondria and close to the sites of energy utilization. In the healthy mammalian heart, the rate of ATP turnover through CK reactions is 5-10 times higher than the rate of ATP synthesis from glycolysis and oxidative phosphorylation combined (Saupe et al. 2000).

\section{Muscle adaptation in the context of CK deficiency in mice}

The importance of the CK system in cellular bioenergetics has been highlighted by experiments using mice with a gene knockout of either the sarcomeric mitochondrial isoform of

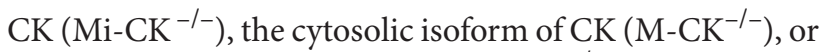
a combination of both isoenzymes $\left(\mathrm{CK}^{-/-}\right)$(van Deursen et al. 1993; Steeghs et al. 1997). Loss of MM-CK does not cause a compensatory increase in the $\mathrm{Mi}-\mathrm{CK}_{\mathrm{s}}$ (Veksler et al. 1995). Loss of both MM-CK and Mi-CK has no effect on the normal post-partum decrease in $\mathrm{BB}-\mathrm{CK}$ in adult heart and skeletal muscles (Saupe et al. 2000).

Total CK activity was reduced in mice that possessed a knockout of Mi-CK (70\% of normal CK activity) and of MM-CK (28\% of normal CK activity), compared to wild-type animals (van Deursen et al. 1993; Steeghs et al. 1997). When both $\mathrm{Mi}-\mathrm{CK}_{\mathrm{s}}$ and MM-CK were absent, total CK activity was reduced to $\sim 4 \%$ (Steeghs et al. 1997).

$\mathrm{CK}^{-/-}$mice are fully viable (Steeghs et al. 1997). However, CK-deficiencies profoundly affected the ability of mice to exhibit spontaneous activity (Momken et al. 2005). $\mathrm{CK}^{-/-}$mice had lower exercise capacities and their maximum running speed was $50 \%$ lower than in wild-type mice.

\section{Architectural and functional remodeling in cardiac cells}

The physiological phenotype of hearts with deleted CK genes is of clinical interest, since the failing myocardium in many different etiologies is characterized by changes in myocardial energetics, including decreased total CK activity and large changes in the relative amounts of the CK isoforms in the myocardium (Ingwall 1993; Nascimben et al. 1996; Ye et al. 2001; Spindler et al. 2004).

Initial reports revealed that those mice that lack one or both of the MM-CK and $\mathrm{Mi}-\mathrm{CK}_{\mathrm{s}}$ isoforms developed nearly normal cardiac function under moderate workload conditions (Steeghs et al. 1997). Nahrendorf et al. (2005) used 
cardiac magnetic resonance imaging (MRI) to discover that ablation of CK isoenzymes leads to substantial adaptational changes in the heart. The $\mathrm{Mi}-\mathrm{CK}^{-/-}$and $\mathrm{CK}^{-/-}$mice developed substantial left ventricular dilatation and significant cardiac hypertrophy. Compared to wild-type mice, there were striking 73 and $64 \%$ increases in left ventricular mass. Presence of cardiomyocyte hypertrophy was confirmed through measuring the cross-sectional areas of wild-type and $\mathrm{CK}^{-1-}$ hearts. $\mathrm{CK}$-deficient mice exhibited increased expression of MHC- $\beta$ (myosin heavy chains), which are considered markers of myocardial hypertrophy (Small and Krieg 2004). The use of MRI techniques to measure myocardial perfusion and mechanics allowed these researchers to detect the abnormalities in the $\mathrm{CK}^{-/-}$phenotype. The myocardium in $\mathrm{CK}^{-/-}$mice was characterized by reduced perfusion and a reduced maximum contraction velocity (Nahrendorf et al. 2006).

These physiological results were consistent with electron microscopy results. Hearts from CK-deficient mice were characterized by alterations in mitochondrial volume and by a larger number of lipid droplets adjacent to the intermyofibrillar mitochondria (Steeghs et al. 1997). Later, Kaasik et al. (2001) showed marked cytoarchitectural reorganization of cardiac muscle. Frequent splitting of myofibrils resulted in the formation of thinner myofilament bundles and their deviation from the longitudinal direction. Abundant mitochondria filled all the space between myofibrils.

Given the aforementioned ultrastructural observations and the results of contractile kinetics and oxygen consumption measurements, Kaasik et al. (2001) proposed the direct channeling of ATP and ADP among mitochondria and ATP-utilizing structures (in the SR and in the myofibrils). Mitochondria are organized into functional complexes (intracellular energetic complexes) with adjacent ATP-utilizing systems (Saks et al. 2001). ADP is probably directly channeled from mitochondria to other ATPases in the context of reduced diffusion in the cytosol. Inside these complexes, mitochondrial functional state apparently depends on the state of the sarcomere and related structures (Adrienko et al. 2003).

\section{Architectural and functional remodeling in glycolytic skeletal muscle}

Single Mi- $\mathrm{CK}_{\mathrm{s}}$ deficiency had no noticeable effect on morphology and function of the glycolytic skeletal muscles (Steeghs et al. 1997, 1998). M-CK ${ }^{-1-}$ mice showed no alterations in absolute muscle force but they lacked the ability to perform burst-type activity (van Deursen et al. 1993; Veksler et al. 1995). The depressed force production was not accompanied by a slowing relaxation, leading researchers to conclude that there was sufficient ATP to sustain myofibrillar ATPase and $\mathrm{Ca}^{2+}$-ATPase activity (de Haan et al. 1995).

Skeletal $\mathrm{CK}^{-/-}$muscles showed reduced force development and slower relaxation times (Steeghs et al. 1997; Dahlstedt et al. 2001). Functional tests revealed a decreased fatigability of $\mathrm{CK}^{-/-}$fast glycolytic skeletal muscles in comparison to wildtype muscles (Dahlstedt et al. 2001; Gorselink et al. 2001). Total creatine $(\mathrm{Cr})$ concentration was normal (Steeghs et al. 1997; Dahlstedt et al. 2000). Nevertheless, during a period of repeated contractions $\mathrm{PCr}$ was not hydrolyzed in $\mathrm{CK}^{-/-}$muscles, whereas wild-type muscles displayed a noticeable reduction of the PCr/Cr ratio (Dahlstedt et al. 2000; Gorselink et al. 2001). The absence of PCr breakdown during fatigue in $\mathrm{CK}^{-1-}$ fibers negatively impacted the increase in inorganic phosphate ions, which are considered to be a major cause of fatigue (Allen and Westerbland 2001).

Histochemical analysis revealed a shift in myosin isoenzyme expression from fast to slower isoforms in glycolytic skeletal muscles (EDL, psoas, gastrocnemius) in response to MM-CK deficiency (Veksler et al. 1995; Steeghs et al. 1998). A shift towards a more oxidative character of glycolytic muscles in $\mathrm{M}-\mathrm{CK}^{-/-}$and also $\mathrm{CK}^{-/-}$mice suggested an increased intermyofibrillar mitochondrial volume (van Deursen et al. 1993; Steeghs et al. 1997). Stereologic analysis of the mitochondrial volume density of the glycolytic $\mathrm{CK}^{-/-}$muscle fibers (Novotová et al. 2006) revealed that the volume density of both intermyofibrillar and subsarcolemmal mitochondria (beneath the sarcolemma) increased together with their surface densities.

The mean fiber cross-sectional area decreased by $28 \%$ in $\mathrm{CK}^{-/-}$plantaris muscle in comparison to control mice (Momken et al. 2005). A reduction of the average myofibril radius by $18 \%$ was estimated from surface-to-volume density data (Novotová et al. 2006). This can be regarded as an adaptation that improves the supply of contractile myofilaments with calcium and energy substrates in skeletal $\mathrm{CK}^{-/-}$fibers.

The microarchitecture of glycolytic muscle cells can adapt in cases of CK deficiency toward sustaining the contractile function of the muscle cells. As for cardiac cells, in skeletal muscles the increased proximity of mitochondria to contractile fibrils can be considered evidence for ultrastructural adaptation in support of direct energy for contraction activities (Kaasik et al. 2003; Novotová et al. 2006).

In $\mathrm{CK}^{-/-}$plantaris muscle various features of degenerating fibers have been observed. This includes the infiltrates of mononucleated cells in the interstitial areas, collagen deposits (Momken et al. 2005) and membranous inclusions called tubular aggregates (Steeghs et al. 1997; Novotová et al. 2002). Electron microscopic examination of the $\mathrm{CK}^{-/-}$muscles revealed mitochondria containing glycogen, lipofuscin granules and other lysosomal structures (Steeghs et al. 1998). These deposits are common to diseased muscle and occur to a much lesser extent in 
normal muscle as a result of aging (Dubowitz and Sewry 2006).

\section{Architectural and functional remodeling in oxidative skeletal muscle}

Studies of oxidative skeletal muscles in mice that lack specific isoenzymes of CK are not as extensive as studies that focus on glycolytic skeletal muscles. Earlier data were concerned with ultrastructural and histochemical characteristics in response to deficiency of MM-CK. There were no abnormal changes in comparison to control mice (van Deursen et al. 1993).

Subsequently, the enlarged intermyofibrillar mitochondrial volume (1.5-2.0 fold) and increased numbers of lipid droplets were recorded in oxidative $\mathrm{CK}^{-/-}$muscles (Steeghs et al. 1998). Exact quantitative analysis of volume and surface densities remains to be investigated. To date, histological analyses have revealed restricted areas of fiber necrosis characterized by the infiltration of mononucleated cells and myofiber size heterogeneity (Momken et al. 2005). With similar incidence as in glycolytic muscles, fibers with central nuclei have been observed in soleus muscle. The presence of such nuclei is usually considered a marker of myofiber regeneration (Rosenblatt and Woods 1992). The mean fiber cross-sectional area was $36 \%$ lower in $\mathrm{CK}^{-/-}$soleus muscle in comparison to control mice (Momken et al. 2005).

\section{Conclusion}

The CK system exhibits a high degree of plasticity in the context of certain specific muscle functions. It plays a very specific role in excitation-contraction coupling in cardiac and skeletal muscles that cannot be fully compensated for by other pathways (Crozatier et al. 2002). Therefore, understanding the true role of $\mathrm{CK}$ and $\mathrm{Cr}$ within the $\mathrm{CK} / \mathrm{PCr}$ pathway is essential to identify the importance and limits of adaptational processes in muscle cells. We have yet to fully understand the remodeling strategy and extension of cytoarchitectural changes associated with oxidative skeletal muscle fibers.

There is a major need to better understand the status of $\mathrm{CK}$ in the context of malignancy progression in skeletal muscles. Initial findings suggest that $\mathrm{Cr}, \mathrm{PCr}$ and $\mathrm{CK}$ levels decrease as malignancy progresses. Concentrations of all these proteins can reach very low levels in the final stages of sarcoma development (Patra et al. 2008).

At present, there is also growing interest in the role of the $\mathrm{CK} / \mathrm{PCr}$ system in the normal and diseased central nervous system, especially given that CK is expressed in the adult and developing human brain and spinal cord. Observations of the functional impairment of the CK/PCr system reflect the great importance of this system in ensuring normal brain function (Andres et al. 2008).

\section{References}

Allen D. G., Westerblad H. (2001): Role of phosphate and calcium stores in muscle fatigue. J. Physiol. 536, 657-665; doi:10.1111/j.1469-7793.2001.t01-1-00657.x

Andres R. H., Ducray A. D., Schlattner U., Wallimann T., Widmer H. R. (2008): Functions and effects of creatine in central nervous system. Brain Res. Bull. 76, 329-343; doi:10.1016/ j.brainresbull.2008.02.035

Andrienko T., Kuznetsov A. V., Kaambre T., Usson Y., Orosco A., Appaix F., Tiivel T., Sikk P., Vendelin M., Margreiter R., Saks V. A. (2003): Metabolic consequences of functional complexes of mitochondria, myofibrils and sarcoplasmic reticulum in muscle cells. J. Exp. Biol. 206, 2059-2072; doi:10.1242/jeb.00242

Brdiczka D. G., Zorov D. B., Shey S. S. (2006): Mitochondrial contact sites: their role in energy metabolism and apoptosis. Biochim. Biophys. Acta 1762, 148-163

Crozatier B., Badoual T., Boehm E., Ennezat P. V, Guenoun T., Su J., Veksler V., Hittinger L., Ventura-Clapier R. (2002): Role of creatine kinase in cardiac excitation-contraction coupling: studies in creatine kinase-deficient mice. FASEB J. 16, 653-660; doi:10.1096/fj.01-0652com

Dahlstedt A. J., Katz A., Wieringa B., Westerblad H. (2000): Is creatine kinase responsible for fatique? Studies of isolated skeletal muscle deficient in creatine kinase. FASEB J. 14, 982-990

Dahlstedt A. J., Katz A., Westerblad H. (2001): Role of myoplasmic phosphate in contractile function of skeletal muscle: studies on creatine kinase-deficient mice. J. Physiol. 533, 379-388; doi:10.1111/j.1469-7793.2001.0379a.x

Decking U. K., Alves C., Wallimann T., Wyss M., Schrader J. (2001): Functional aspects of creatine kinase isoenzymes in endothelial cells. Am. J. Physiol., Cell Physiol. 281, C320-328

de Haan A., Koudijs J. C. M., Wevers R. A., Wieringa B. (1995): The effects of MM-creatine kinase deficiency on sustained force production of mouse fast skeletal muscle. Exp. Physiol. 80, 491-494

Dubowitz V., Sewry C. A. (2006): Muscle Biopsy: A Practical Approach. ( $3^{\text {rd }}$ edition), Elsevier Health Sciences, England

Dzeja P. P., Zeleznikar R. J., Goldberg N. D. (1998): Adenylate kinase: kinetic behavior in intact cells indicates it is integral to multiple cellular processes. Mol. Cell. Biochem. 184, 169-182; doi:10.1023/A:1006859632730

Dzeja P. P., Terzic A. (2003): Phosphotransfer networks and cellular energetics. J. Exp. Biol. 206, 2039-2047; doi:10.1242/ jeb.00426

Gorselink M., Drost M. R., Coumans W. A., van Kranenburg G. P., Hesselink R. P., van der Vusse G. J. (2001): Impaired muscular contractile performance and adenine nucleotide handling in creatine kinase-deficient mice. Am. J. Physiol., Endocrinol. Metab. 281, E619-625 
Hoerter J., Kuznetsov A., Ventura-Clapier R. (1991): Functional development of the creatine kinase in perinatal rabbit heart. Circ. Res. 69, 665-676

Ingwall J. S. (1993): Is cardiac failure a consequence of decreased energy reserve? Circulation 87, 58-62

in 't Zandt H. J., de Groof A. J., Renema W. K., Oerlemans F. T., Klomp D. W., Wieringa B., Heerschap A. (2003): Presence of (phospho)creatine in developing and adult skeletal muscle of mice without mitochondrial and cytosolic muscle creatine kinase isoforms. J. Physiol. 548, 847-858

Kaasik A., Veksler V., Boehm E., Novotová M., Minajeva A., Ventura-Clapier R. (2001): Energetic crosstalk between organelles: architectural integration of energy production and utilization. Circ. Res. 89, 153-159; doi:10.1161/ hh1401.093440

Kaasik A., Veksler V., Boehm E., Novotová M., Minajeva A., Ventura-Clapier R. (2003): From energy store to energy flux: a study in creatine kinase-deficient fast skeletal muscle. FASEB J. 17, 708-710

Katz A. M. (2001): Physiology of the Heart. ( $3^{\text {rd }}$ edition), Lippincott Williams \& Wilkins, Raven Press, New York

Minajeva A., Ventura-Clapier R., Veksler V. (1996): $\mathrm{Ca}^{2+}$ uptake by cardiac sarcoplasmic reticulum ATPase in situ strongly depends on bound creatine kinase. Pflügers Arch. 432, 904-912; doi:10.1007/s004240050214

Momken I., Lechêne P., Koulmann N., Fortin D., Mateo P., Doan B. T., Hoerter J., Bigard X., Veksler V., Ventura-Clapier R. (2005): Impaired voluntary running capacity of creatine kinase-deficient mice. J. Physiol. 565, 951-964; doi:10.1113/jphysiol.2005.086397

Nahrendorf M., Spindler M., Hu K., Bauer L., Ritter O., Nordbeck P., Quaschning T., Hiller K. H., Wallis J., Ertl G., Bauer W. R., Neubauer S. (2005): Creatine kinase knockout mice show left ventricular hypertrophy and dilatation, but unaltered remodeling post-myocardial infarction. Cardiovasc. Res. 65, 419-427; doi:10.1016/j.cardiores.2004.10.006

Nahrendorf M., Streif J. U., Hiller K. H., Hu K., Nordbeck P., Ritter O., Sosnovik D., Bauer L., Neubauer S., Jakob P. M., Ertl G., Spindler M., Bauer W. R. (2006): Multimodal functional cardiac MRI in creatine kinase-deficient mice reveals subtle abnormalities in myocardial perfusion and mechanics. Am. J. Physiol., Heart Circ. Physiol. 290, H2516-2521; doi:10.1152/ajpheart.01038.2005

Nascimben L., Ingwall J. S., Pauletto P., Friedrich J., Gwathmey J. K., Saks V., Pessina A. C., Allen P. D. (1996): Creatine kinase system in failing and non failing human myocardium. Circulation 94, 1894-1901

Novotová M., Zahradník I., Brochier G., Pavlovičová M., Bigard X., Ventura-Clapier R. (2002): Joint participation of mitochondria and sarcoplasmic reticulum in the formation of tubular aggregates in gastrocnemius muscle of $\mathrm{CK}^{-/-}$ mice. Eur. J. Cell Biol. 81, 101-106; doi:10.1078/01719335-00230

Novotová M., Pavlovičová M., Veksler V. I., Ventura-Clapier R., Zahradník I. (2006): Ultrastructural remodeling of fast skeletal muscle fibers induced by invalidation of creatine kinase. Am. J. Physiol., Cell Physiol. 291, C1279-1285; doi:10.1152/ajpcell.00114.2006
Patra S., Bera S., SinhaRoy S., Ghoshal S., Ray S., Basu A., Schlattner U., Wallimann T., Ray M. (2008): Progressive decrease of phosphocreatine, creatine and creatine kinase in skeletal muscle upon transformation to sarcome. FEBS J. 275, 3236-3247; doi:10.1111/j.1742-4658.2008.06475.x

Rosenblatt J. D., Woods R. I. (1992): Hypertrophy of rat extensor digitorum longus muscle injected with bupivacaine. A sequencial histochemical, immunohistochemical, histological and morphometric study. J. Anat. 181, 11-27

Rossi A. M., Eppenberger H. M., Volpe P., Cotrufo R., Wallimann T. (1990): Muscle-type MM creatine kinase is specifically bound to sarcoplasmic reticulum and can support $\mathrm{Ca}^{2+}$ uptake and regulate local ATP/ADP ratios. J. Biol. Chem. 265, 5258-5266

Saks V. A., Khuchua Z. A., Vasilyeva E. V., Belikova O. Y., Kuznetsov A. V. (1994): Metabolic compartmentation and substrate channelling in muscle cells - role of coupled creatine kinase in in vivo regulation of cellular respiration - a synthesis. Mol. Cell. Biochem. 133, 155-192; doi:10.1007/ BF01267954

Saks V. A., Kaambre T., Sikk P., Eimre M., Orlova E., Paju K., Piirsoo A., Appaix F., Kay L., Regitz-Zagrosek V., Fleck E., Seppet E. (2001): Intracellular energetic units in red muscle cells. Biochem. J. 356, 643-657; doi:10.1042/02646021:3560643

Saupe K. W., Spindler M., Tian R., Ingwall J. S. (1998): Impaired cardiac energetics in mice lacking muscle-specific isoenzymes of creatine kinase. Circ. Res. 82, 898-907

Saupe K. W., Spindler M., Hopkins J. C. A., Shen W., Ingwall J. S. (2000): Kinetic, thermodynamic, and developmental consequences of deleting creatine kinase isoenzymes from the heart. J. Biol. Chem. 275, 19742-19746; doi:10.1074/jbc. M001932200

Small E. M., Krieg P. A. (2004): Molecular regulation of cardiac chamber-specific gene expression. Trends Cardiovasc. Med. 14, 13-18; doi:10.1016/j.tcm.2003.09.005

Spindler M., Meyer K., Strömer H., Leupold A., Boehm E., Wagner H., Neubauer S. (2004): Creatine kinase-deficient hearts exhibit increased susceptibility to ischemia-reperfusion injury and impaired calcium homeostasis. Am. J. Physiol., Heart Circ. Physiol. 287, H1039-1045; doi:10.1152/ ajpheart.01016.2003

Steeghs K., Benders A., Oerlemans F., de Haan A., Heerschap A., Ruitenbeek W., Jost C., van Deursen J., Perryman B., Pette D., Bruckwilder M., Koudijs J., Jap P., Veerkamp J., Wieringa B. (1997): Altered $\mathrm{Ca}^{2+}$ responses in muscles with combined mitochondrial and cytosolic creatine kinase deficiencies. Cell 89, 93-103; doi:10.1016/S00928674(00)80186-5

Steeghs K., Oerlemans F., de Haan A., Heerschap A., Verdoodt L., de Bie M., Ruitenbeek W., Benders A., Jost C., van Deursen J., Tullson P., Terjung R., Jap P., Jacob W., Pette D., Wieringa B. (1998): Cytoarchitectural and metabolic adaptations in muscles with mitochondrial and cytosolic creatine kinase deficiencies. Mol. Cell. Biochem. 184, 183-194; doi:10.1023/A:1006811717709

Tullson P. C., Rush J. W. E., Wieringa B., Terjung R. L. (1998): Alterations in AMP deaminase activity and kinetics in 
skeletal muscle of creatine kinase-deficient mice. Am. J. Physiol., Cell Physiol. 274, C1411-1416

van Deursen J., Heerschap A., Oerlemans F., Ruitenbeek W., Jap P., ter Laak H., Wieringa B. (1993): Skeletal muscles of mice deficient in muscle creatine kinase lack burst activity. Cell 74, 621-631; doi:10.1016/0092-8674(93)90510-W

Veksler V. I., Kuznetsov A. V., Anflous K., Mateo P., van Deursen J., Wieringa B., Ventura-Clapier R. (1995): Muscle creatine kinase-deficient mice. II. Cardiac and skeletal muscles exhibit tissue-specific adaptation of the mitochondrial function. J. Biol. Chem. 270, 19921-19929

Vendelin M., Lemba M., Saks V. A. (2004): Analysis of functional coupling: mitochondrial creatine kinase and adenine nucleotide translocase. Biophys. J. 87, 696-713; doi:10.1529/ biophysj.103.036210

Ventura-Clapier R., Veksler V. I., Hoerter J. A. (1994): Myofibrillar creatine kinase and cardiac contraction. Mol. Cell. Biochem. 133, 125-144; doi:10.1007/BF01267952

Ventura-Clapier R., Kuznetsov A., Veksler V. I., Boehm E., Anflous K. (1998): Functional coupling of creatine kinases in muscles: species and tissue specificity. Mol. Cell. Biochem. 184, 231-247; doi:10.1023/A:1006840508139

Ventura-Clapier R., Kaasik A., Veksler V. (2004): Structural and functional adaptations of striated muscles to CK deficiency. Mol. Cell. Biochem. 256-257, 29-41; doi:10.1023/B: MCBI.0000009857.69730.97

Wallimann T., Eppenberger H. M. (1985): Localization and function of M-line-bound creatine kinase M-band model and creatine phosphate shuttle. Cell Muscle Motil. 6, 239-285

Wallimann T., Schnyder T., Schlegel J., Wyss M., Wegmann G., Rossi A. M., Hemmer W., Eppenberger H. M., Quest A. F. G. (1989): Subcellular compartmentation of creatine kinase isoenzymes, regulation of CK and octameric structure of mitochondrial CK: important aspects of the phosphoryl-creatine circuit. Prog. Clin. Biol. Res. 315, 159-176

Wallimann T., Wyss M., Brdiczka D., Nicolay K., Eppenberger H. M. (1992): Intracellular compartmentation, structure and function of creatine kinase isoenzymes in tissues with high and fluctuating energy demands: the phosphocreatine circuit for cellular energy homeostasis. Biochem. J. 281, 21-40

Wilding J. R., Joubert F., De Araujo C., Fortin D., Novotová M., Veksler V., Ventura-Clapier R. (2006): Altered energy transfer from mitochondria to sarcoplasmic reticulum after cytoarchitectural perturbations in mice hearts. J. Physiol. 575, 191-200; doi:10.1113/jphysiol.2006.114116

Wyss M., Smeitink J., Wevers R. A., Wallimann T. (1992): Mitochondrial creatine kinase: a key enzyme of aerobic energy metabolism. Biochim. Biophys. Acta 1102, 119-166; doi:10.1016/0005-2728(92)90096-K

Xu K. Y., Zweier J. L., Becker L. C. (1995): Functional coupling between glycolysis and sarcoplasmic reticulum $\mathrm{Ca}^{2+}$ transport. Circ. Res. 77, 88-97

Ye Y., Gong G., Ochiai K., Liu J., Zhang J. (2001): High-energy phosphate metabolism and creatine kinase in failing hearts: a new porcine model. Circulation 103, 1570-1576

Zoll J., Sanchez H., N'Guessan B., Ribera F., Lampert E., Bigard X., Serrurier B., Fortin D., Geny B., Veksler V., VenturaClapier R., Mettauer B. (2002): Physical activity changes the regulation of mitochondrial respiration in human skeletal muscle. J. Physiol. 543, 191-200; doi:10.1113/ jphysiol.2002.019661

Received: May 22, 2008

Final version accepted: December 8, 2008 